\title{
Exploring the use of loT Data for Heightened Situational Awareness in Centralised Monitoring Control Rooms
}

\author{
Flávio Horita ${ }^{1,2}$ (D) . João Baptista ${ }^{2}$ (D) . João Porto de Albuquerque A $^{(D)}$
}

Accepted: 5 October 2020 / Published online: 16 November 2020

(C) The Author(s) 2020

\begin{abstract}
This paper traces the expansion of a network of IoT sensors to improve the effectiveness of a centralised control room in Brazil in anticipating natural hazards. This centralised model relies on using IoT data by highly qualified experts replacing previous smaller local structures. We draw on the notion of Situational Awareness to carry out the study. Results show that although the operators were not always familiar with the characteristics of locations, the use of IoT data heightened their situational awareness in the centralised control room by improving perception and comprehension. However, they still relied on local knowledge and learned experiences to support projection and anticipation of risks. The study highlights that although data analytics systems are capable of expanding operators' perception of local elements, they must be complemented by local richer forms of information, needed to anticipate risks and make critical decisions with major impact on local population.
\end{abstract}

Keywords Situation awareness · Centralised monitoring control room · IoT big data · Disaster risk monitoring · Digital transformation · Advanced ICT

\section{Introduction}

Digital technology can support critical decision making, and sometimes these decisions could be the difference between life or death when they are used to anticipate disasters triggered by natural hazards, particularly in poor regions of the world (Sakurai and Murayama 2019). Our study followed the deployment of a new national network of Internet-of-Things (IoT) weather sensors and the development of a centralised control room with advanced

Flávio Horita

flavio.horita@ufabc.edu.br

João Baptista

j.baptista@wbs.ac.uk

João Porto de Albuquerque

j.porto@warwick.ac.uk

1 Center for Mathematics, Computing and Cognition, Federal University of ABC, Santo André, Brazil

2 Warwick Business School, University of Warwick, Coventry, UK

3 Institute of Global Sustainable Development, University of Warwick, Coventry, UK computational capabilities and qualified experts to anticipate natural hazards across Brazil. This new infrastructure of sensors and the central monitoring control room replace a fragmented system that relied on local teams with limited resources and knowledge to recognise and respond to natural hazards. We have followed the expansion of this network and the development of the Brazilian National Centre for Disaster Monitoring and Early Warning System (Cemaden) since 2016. Cemaden's mission is centred on monitoring weather conditions to issue warnings of likely natural disasters such as droughts, landslides, floods, and flash floods (Horita et al. 2018). To support this aim, highly qualified experts working in a centralised monitoring team rely on a sensor network for environmental monitoring (e.g., water level and volume of rainfall). This network expanded the number of installed rainfall gauges from 258 in 2012, 856 in 2014 and then 2500 in 2015 and to 4375 in 2019. The ultimate aim of this project was to create data-driven predictive models developed by the qualified experts of the relevant weather and geographical disciplines using advanced computational capabilities. We studied the expansion of the IoT network to improve data feeds and capture how this centralised structure improved processes of decision making, with an emphasis on the way critical local knowledge is used to make decisions. Overall, the study captures and 
conceptualises the way Cemaden uses digital technologies to improve the situational awareness of highly qualified knowledge operators in a new centralised disaster monitoring network.

One of the key driving forces for the creation of Cemaden as a centralised data-driven monitoring system was to improve decision making (Horita et al. 2017; Horita et al. 2018). This is because IoT supplies big data so that "managers can measure, and hence know, radically more about their businesses, and directly translate that knowledge into improved decision making and performance" (McAfee and Brynjolfsson 2012, p. 4). This notion can also be extended to disaster risk management since IoT sensors contribute to the monitoring of vulnerable locations, which in turn has the potential to support better decisions (Shah et al. 2019). However, these advanced technologies create new decision making dynamics with the potential to have deep transformative effects in the organisation itself (Fitzgerald et al. 2014; Baptista et al. 2020). For example, new skills and internal capabilities are needed to feed appropriate data into the machine learning algorithms, to interpret relevant results, and eventually to use the results as an input to new action and decisions (von Krogh 2018). These new technologies have therefore the potential to enhance decision making, while at the same time creating tensions and unintended effects that may disrupt established organisational structures and business models (Shrestha et al. 2019; Burton et al. 2019; Grønsund and Aanestad 2020). In fact, Wessel et al. (2020) suggest that digital transformation goes beyond IT-enabled organisational transformation when the use of technology for decision making also entails deeper changes to business models and reshapes the identity of the organisation, with potential to eventually lead to wider modifications on external society (Verhoef et al. 2019). This is particularly true in the case of Cemaden because the use of IoT data for environmental monitoring and disaster early-warning processes is associated with larger societal changes as regards to the way natural hazards are anticipated and dealt with at national level.

We trace the adoption of a particular type of technology based on data from a network of IoT weather sensors (Velev 2011), and the development of centralised computer models to process the vast amount of IoT sensors. IoT is behind the recent shifts towards "Industry 4.0 " as a crucial means to gather data on vital aspects of business processes, which when properly analysed can lead to the identification of areas of organisations and business that require attention (Yang et al. 2013; Bordeleau and Felden 2019). The promise with IoT is that with the vast amount of detailed and more accurate and real-time data, qualified managers can develop powerfull computational models to comprehend the overall complexity of situations and improve decision making. In the case of the Cemaden, the network of IoT sensors was created to improve critical decision making in managing natural hazards and replace a fragmented structure of dispersed local teams. This is because IoT would provide timely information directly from the ground to allow qualified experts to better manage emerging risks and coordinate with response teams on the ground (Schwertner et al. 2018).

Our study is particularly concerned with the ability of the IoT sensors to provide sufficient understanding or awareness of local conditions to the qualified experts in the central control room to make vital decisions remotely from the events on the ground. We draw on the concept of Situational Awareness to analyse the effects of shifting highly contextual decisions from local teams to a centralised body of experts with more computational capabilities based on IoT data.

Situational awareness is important for decision making to ensure that there is sufficient "perception of the elements in the environment [...], the comprehension of their meaning, and the projection of their status in the near future" (Endsley 1988, p. 97). Situational Awareness is an established area of research in engineering, human behaviour and cognition sciences with applications to aviation, command and control rooms, military, and emergency response services (Gorman et al. 2006; Valecha et al. 2012). Scholars in the Information Systems (IS) field have also investigated situational awareness as an influencing factor on decentralised collaboration and communication (Stieglitz et al. 2017), as well as on individual and group decision making (Rohmeyer and Zvi 2009).

There is however limited research in IS capturing organisational effects of using IoT for supporting situation awareness in critical decision making. To fill this gap, we adopt an in-depth qualitative case study research strategy at Brazil's early-warning centre (Cemaden) to conceptualise organisational dimensions of utilising IoT weather sensors to support situational awareness in centralised monitoring control rooms.

Our main motivations for this study are therefore twofold. First, we aim at improving our understanding of how IoT weather sensors can improve situational awareness of centralised monitoring control rooms for disaster response. More accurate information for decision making is critical in this context and could make communities more resilient to extreme events and natural hazards, and thus contribute to the United Nations' 2030 Sustainable Development Goals (Messerli and Murniningtyas 2019). Second, we expect to capture transformational effects on the structure of organisations that manage critical decisions based on large scale IoT data centralised control rooms, which is increasingly a salient area of research (Fitzgerald et al. 2014; Verhoef et al. 2019). We address 
this by analysing organisational dynamics of a centralised monitoring control room instead of relying on dispersed local structures for monitoring local conditions.

More specifically we seek to answer the following research question:

RQ) "How does data from IoT sensors impact on situational awareness in centralised critical decision making?".

For investigating this question, we conducted an in-depth qualitative case study of Cemaden's adoption of IoT weather sensors (e.g., rainfall gauges and weather radar systems) and their integration in critical decision making in disaster risk management.

After this introductory section, this paper is organised as follows. Section 2 reviews key literature on digital transformation and IoT as context for the study. Section 3 provides the conceptual background showing key notions of situational awareness. Section 4 introduces the research methodology, in particular, the case study approach employed for data collection and analysis. Next, Section 5 presents the findings covering the following themes: technology and human properties, and mediating conditions affecting situational awareness. Section 6 discusses findings using concepts from situational awareness theory. Eventually, Section 7 concludes and proposes future lines of work.

\section{IoT as a Precursor for Digital Transformation}

Technology such as IoT sensors and advanced computational capabilities have the potential to enhance organisational decision making, but it also disrupts patterns and structures of organising. It is therefore important to capture deeper effects of adopting advanced technology in organisations managing critical infrastructure at national level.

Digital transformation can have many different forms and effects (Wessel et al. 2020). From the evolution of smartphones bringing together communities and organisations (Hausberg et al. 2019) to the emergence of entirely new industries such as Uber as a disruptive player that reformed, reorganised, and thus transformed the automotive industry from ride-hailing apps or car-sharing (Cramer and Krueger 2016; Hinings et al. 2018). Similarly, AirBnb changed the hospitality industry with consequences for tourism and tourist destinations (Oskam and Boswijk 2016). Although several definitions have been offered to explain digital transformation, Fitzgerald et al. (2014, p. 2) suggests that digital transformation involves "the use of new digital technologies to enable major business improvements, such as enhancing customer experience or creating new business models". However, Wessel et al. (2020, p. 44) make an important distinction between "digital transformation" and "IT organisational transformation", suggesting that digital transformation "involves using digital technology in order to (re)define a value proposition and to change the identity of the firm, whereas IT organisational transformation involves using digital technology to support an existing value proposition and reinforce an existing organisational identity." This distinction is important particularly because it helps us see how deep the adoption of the technology has affected the nature of organising beyond the intended but more superficial improvements in decision making.

In the case of IoT, data from IoT sensors have the potential to support several key organisational functions such as marketing strategies by gathering real time customers' shopping behaviour and preferences and then use these data to support forecasting of customer needs (Lo and Campos 2018). IoT can also be used to improve waste management and monitoring in cities by warning collectors when inhabitants' bins reach capacity (Lundin et al. 2017), and therefore allowing for more effective and productive use of resources. Sakurai and Murayama (2019) stress that digital technologies (e.g., sensors, open satellite images and UAVs) can help local governments to monitor real-time situations of infrastructure, social care, and rivers, and land. Finally, IoT interconnects components, devices, and users located both inside or outside the organisations, which make it possible to connect multiple facilities remotely (Hazen et al. 2016). Westerlund et al. (2014) highlights that IoT encourages a shift from firm-based business models to business model ecosystems that consist of monitoring sensors and components established to support strategic value.

These studies all indicate the potential of IoT in providing real time contextual information of dispersed locations feeding this information to centralised decision makers (Sheth 2016). For example, a hydrological station using IoT to monitor the water level of a riverbed by emergency agencies. This information can then be the basis to improve awareness of local conditions by capturing realtime and comprehensive data about the ongoing scene, which then leads to a fast and more accurate awareness of individuals (Seebach et al. 2011; Yang et al. 2013), and eventually, this enhanced awareness leads to better decision making (Wickler and Potter 2009).

However, the challenge is when organisations shift their decision making process to rely on data from IoT sensors to make critical decisions. As discussed above, we need to better understand the deeper effects of this on the decision making process and on the structure of organisations, which go beyond first and second level order effects (Baptista et al. 2020), and the situational awareness literature provides us with a conceptual basis to do this. We address these questions by carrying a qualitative in-depth research study of an early-warning monitoring centre in Brazil. This centre 
was set up to improve disaster resilience and thus contribute to the United Nation's 2030 Sustainable Development Goals 11 (Sustainable Cities) and 13 (Climate Action) (Messerli and Murniningtyas 2019). The next section reviews the concept of situational awareness to develop the conceptual background of our study.

\section{Conceptual Background: Situational Awareness}

Situational awareness is integral to critical decision making, particularly in control rooms that manage risk and response to potentially catastrophic natural hazards. Control rooms can be centralised structures with highly qualified experts analysing vast amounts of data using advanced computational models to make life-saving decisions (Schulman and Roe 2011). This centralisation of specialised knowledge improves information flow and exchange among the control room operators (Stanton and Roberts 2020) and facilitates the analysis of existing alternatives from different perspectives of interest towards a better decision making (Horita et al. 2018). Since there might be an overload of information arriving into the control room during hazardous situations, the information sharing should be centralised on a specific role (coordinator) in order to improve situational awareness (de Walle et al. 2016). However, the centralised nature of these control rooms means that these experts make critical decisions based on data from remote locations, and therefore have an abstract view of the local situation and conditions (Stevens-Adams et al. 2015). Developing situational awareness in control rooms is therefore critical to ensure that decisions are as accurate and contextually relevant as possible, while relying on data and conceptual models. For example, a geologist needs information about rainfall and the humidity in the soil from a vulnerable location to decide whether or not to issue a warning of a potential landslide, but this data alone will provide a limited perspective of the actual risk to the population as this depends on specific natural and social conditions of the local setting (Stanton et al. 2001). Although there is value to study situational awareness in this context at team level we focused on the individual level as a first and valuable step towards better understanding this phenomena. Future studies can progress this line of inquire forward to study team level situational awareness.

Situational awareness has roots in engineering and military research of the 1980s, but its use and influence in academic research in management and organisations expanded in the 1990s. Despite some variations, authors converge on a view of situational awareness as the need to have a comprehensive view of a situation in real time in order to anticipate future events. Technology that allows for situational awareness needs to capture essential elements of the environment and present them in a clear and organised way to decision makers, who then process this information through established mental models to make critical decisions. For example, Sarter and Woods (1991, p. 52) emphasise the need to capture a comprehensive view of a situation to create situational awareness, they say that "the accessibility of a comprehensive and coherent situation representation which is continuously being updated in accordance with the results of situation assessments". However, most studies draw on the definition of situational awareness using Mica Endsley's seminal paper of 1989 which specifies three key elements of situational awareness which include perception of elements (initial capturing of essential elements of a situation), comprehension of the meaning of these elements (understanding of these elements in relation to their importance and significance) and projection of their significance to the future (ability to anticipate the impact of these elements to future events) (Endsley 1988, p. 97).

The concept of perception has a central role in situational awareness. It is one's perception (e.g., aeroplane pilot) of the elements (e.g., terrain location) in the environment that leads to the comprehension (e.g., the ability to reach the destination) and projection (e.g., projected areas of severe weather) of contextual elements (Endsley 1988, 2015). While perception consists of acknowledging the elements of the environment, lessons learned from past situations and acquired experiences have a great potential to refine and improve the analytical process towards a better decision maker's perception. Therefore, the expertise in relevant domain influences not only when analysing and choosing amongst the existing alternatives, but also on the outcome of a decision which then provides awareness of a situation (Cak et al. 2020). On the other hand, the acquired expertise also allows decision makers to cope with the high volume of information by narrowing down complex information to only elements that are required to comprehend and project the situation (Endsley et al. 2000).

This shows the importance of previous experience and contextual understanding in gaining situational awareness. For example, previous experience of a surgeon configures patterns and mental models that enable faster and more suitable decisions in the course of a surgery. Further, experts and novices rely on technical knowledge built on working memory and long-term memory to process elements of the environment and context using patterns of recognition to anticipate future events (Fracker 1991; Cak et al. 2020). Working memory represents an activated subset of cognition elements recovered from the long-term memory for understanding a particular situation (Endsley et al. 2000). Situational awareness is therefore also derived from an individual's ability to process data, i.e., the ability 
to perceive and analyse information of the current situation from various sources and with different quality (Endsley et al. 2000). Together, data processing abilities and working memory capacities are fundamental to improve situational awareness (Jipp and Ackerman 2016).

Technology can enhance and increase the availability of data to decision makers, for example using IoT sensors to provide real-time data of a local context using wireless sensor networks as showed by Yang et al. (2013). Information systems can also help present complex information in a more organised and structured way to decision makers through well- designed dashboards and decision support systems. This expands the comprehension of the environment of decision makers, even in cases where they lack understanding of local contextual conditions (Stanton et al. 2001).

The use of vast amounts of IoT sensor data processed using advanced computational models increases automation of decisions (Velev 2011) leaving humans to check and improve the models and make informed decisions based on results. Greater automation involves processing large volumes of data using advanced computational models, therefore, augmenting and assisting humans in the analysis (Wickens 1996; Rai et al. 2019). However, automated systems may degrade humans' knowledge of the environment (Wickens 1996) and "even when full automation of a task may be technically possible, it may not be desirable if the performance of the joint human-machine system is to be optimised" (Endsley 1995, p. 204). To avoid this, Endsley (2018) and Wickens (1996) recommend a desirable balance in human-system automation to develop situational awareness by decision makers. This was expanded by (Hawkley et al. 2005) who proposed the concept of human supervisory control where the data analytics system assists decision makers in their tasks.

Situational awareness has been used as a conceptual basis to study various aspects of organisations, such as team awareness (Gorman et al. 2006; Prince et al. 2007), members' training (Salas et al. 1995) and communication (Mancheva and Dugdale 2016). Recent research has paid particular attention to the role of technology in achieving situational awareness within organisations. Seebach et al. (2011) showed that workplace technology, such as an enterprise microblogging allows employees to be more aware of job roles and ongoing discussions. This was further developed by Leonardi (2015) showing that enterprise social media improves ambient awareness and knowledge acquisition, ultimately contributing to improving situational awareness of individuals. Furthermore, Loebbecke and Palmer (2006) provided evidence that IoT technology (e.g., RFID) permit inventory tracking and real-time data sharing that help managers and directors gain awareness of complex supply chain processes (e.g., the volume of inventory, location of items, or delivery routes). However, we notice a significant research gap in the current absence of research investigating the implications of IoT to decision-making related to critical contexts such as disaster management.

\section{Research Methods}

This study uses an in-depth qualitative case study research approach to explore the decision making process of the centralised monitoring control room, as well as the use of IoT weather sensors for supporting such decisions. An in-depth case study research approach is appropriate in this study as we investigate a contemporary phenomenon in its context (Yin 2002) with a view to gaining a deeper understanding of this phenomenon (Runeson and Höst 2008). We use qualitative research to allow the interpretation and development of this deepder understanding (Klein and Myers 1999). We use semi-structured interviews as na appropriate data collection approach, to allow for richer insights by leaving space for participants to express their opinions in a more free-to-talk approach. The semi-structured interview method was chosen to allow for a more open-ended approach. It is also more dynamic allowing for adjusting line of inquire and course correction on the part of the interviewer. They also allow scope for a wider and fuller exploration of the objects of study (Runeson and Höst 2008). Questions were planned to carry out the interviews, but they are not necessarily asked in exactly the same order and with the precision as listed (Seaman 1999).

The research focuses on the National Centre for Monitoring and Early Warning of natural hazards (Cemaden) located in São José dos Campos, a city 60km near São Paulo City. This centre is responsible for gathering environmental data in Brazil and issuing warning messages of upcoming natural hazard events to trigger responsive actions of the populations potentially affected by disasters.

\subsection{Data Collection}

Data were collected in two different periods of time. First, we conducted direct observations and 8 semistructured interviews in January and February of 2016 at the Cemaden's headquarters in São José dos Campos, Brazil. This provided qualitative data explaining the work conditions and decision process used by the control room operators. Interviews were conducted by following six semistructured questions (see Appendix A) and lasted between 30 and 50 minutes each.

The data collection was centred on the use of information and data required by activities, which are performed in the control room. Purposive sampling was adopted for selecting participants for the interviews and observations, 
i.e., the participants were selected based on the potential to contribute to elucidate the research question, instead of a random selection within the population. We selected operators working at their workstations as participants in the study. This approach was chosen because operators should not be distracted from their vital work at Cemaden so we had to minimise disrupting their normal activities. Therefore, we approached them spontaneously between working shifts but tried to use these short moments with them to focus our efforts on the objectives of the research. Our aim was to recruit as many participants as possible in order to achieve a comprehensive view of their practices. Table 1 summarises the participants of the first round of interviews.

A second round of semi-structured interviews was carried out in November 2019 for gathering up-to-date information on the use of new technology by control room operators. On this occasion, the interviews were conducted remotely and lasted around 30-50 minutes. The analysis of data collected in the first round of interviews provided valuable insights and lessons learned about the monitoring control room that led to further inquiries and research questions. These elements were included in the guiding questionnaire of this second round of data collection comprising 10 semi-structured questions (see Appendix B).

While in the first part of the study our aim was to develop a broader understanding of the organisational setting within the monitoring control room, the second part was more focused on exploring specific viewpoints and issues emerging from the literature and conceptual framework. We further aimed at understanding the role of the data analytics systems on the activities performed in the control room. That required approaching other operators to participate in the interviews too, besides the early participants. Convenient sampling was thus adopted, also based on previous knowledge of the control room operators. Invitations were sent via email to a further stage of data collection, resulting in four acceptances to take part in an extended exploration of relevant parts of the study. Interviews were then carried out via video-conference either on Skype or Whatsapp and lasted up to 40 minutes. Table 2 details the participants of the second round of interviews.

Data from the interviews allowed us not only to analyse the interviewees' perceptions about the topic but also to gain a more detailed understanding of the transformational effects in shifting to the new centralised model based on data from IoT.

\subsection{Data Analysis}

After the data collection, the audio recorded from both rounds of interviewers was transcribed to facilitate our data analysis. To analyse the transcript data, we adopted (Gioia et al. 2013)'s methodology for inductively raising and aggregating theoretical themes and dimensions on the use of IoT weather sensors for critical decision making within the centralised monitoring control room. We used the NVivo Data Analysis Software (version 10) as a tool for supporting the coding of data and theoretical analysis. Figure 1 outlines the data analysis approach following three phases.

As shown in Fig. 1, the phases were threefold. First, we carried out an open coding on the transcriptions to identify emergent themes and select representative quotes of these themes. We then organised those quotes around themes creating 1st-order concepts about the phenomenon. Open coding is "the analytic process through which concepts are identified and their properties and dimensions are discovered in data" (Strauss and Corbin 1998, p. 101). Second, these derived concepts were then refined on 2ndorder themes that reflect the meaning of a group of related concepts. For defining the most suitable themes, we completed an interactive cycle of axial coding focused on analysis, discussions, and refinements. While open coding is a process of labelling sentences of interest in the text, axial coding focuses more on relating existing codes to each other (Strauss and Corbin 1998). It is worth noting that in this step the emerging themes were also theoretically developed by means of existing literature. Finally, the remaining themes
Table 1 Participants of the first round of interviews

\begin{tabular}{llllll}
\hline ID & Role & Experience & Degree & Background & Gender \\
\hline S1-1 & Meteorologist & $>3$ years & PhD & Meteorology & Male \\
S1-2 & Meteorologist & $>3$ years & MSc & Meteorology & Male \\
S1-3 & Geologist & $<=2$ years & MSc & Geography & Male \\
S1-4 & Geologist & $>3$ years & MSc & Geology & Male \\
S1-5 & Hydrologist & $<=2$ years & MSc & Environ. Eng. & Male \\
S1-6 & Disaster analyst & $>3$ years & PhD & Meteorology & Male \\
S1-7 & Hydrologist & $<=2$ years & MSc & Civil Eng. & Male \\
S1-8 & Disaster analyst & $>3$ years & PhD & Remote sensing & Female \\
\hline
\end{tabular}


Table 2 Participants of the second round of interviews

\begin{tabular}{lllllll}
\hline ID & Role & Experience & Degree & Background & Gender & Was he/she on the first round? \\
\hline S2-1 & Geologist & $<5$ years & PhD & Meteorology & Male & New \\
S2-2 & Geologist & $<5$ years & MSc & Meteorology & Male & New \\
S2-3 & Geologist & $<4$ years & MSc & Geography & Male & S1-3 \\
S2-4 & Disaster analyst & $<5$ years & MSc & Geography & Male & S1-4 \\
\hline
\end{tabular}

were again revisited on a selective coding approach for establishing aggregate dimensions that summarise the key effects associated with the phenomenon. Selective coding is recognised as "the process of choosing one category to be the core category" (Strauss and Corbin 1998).

\subsection{Case Study}

Cemaden focuses on monitoring environmental variables related to droughts, landslides, floods, and flash floods as these are the main hazardous events that often occur in Brazil. For example, the Northwest of Brazil faces critical issues with droughts, while gradual floods are more frequent in the North region. Forest fires also happen in the North and Central regions. However, floods and landslides are the most critical issues in Brazil, the impact of natural hazards in cities are significant (Haddad and Teixeira 2015), contributing to deep social structural problems in the country (Marengo and Espinoza 2016).

Since the establishment of Cemaden in São José dos Campos, São Paulo, in 2011, the number of monitored municipalities has grown from 56 in 2011 to almost 1,000 in 2016, which represents $17 \%$ of all Brazilian municipalities $(5,570$ cities $)$. This growth reflects an increase in the number of warnings issued by the monitoring control room of Cemaden in recent years, from 1353 warnings in 2014 to 1762 warnings in 2015, and 1983 warnings in 2016.

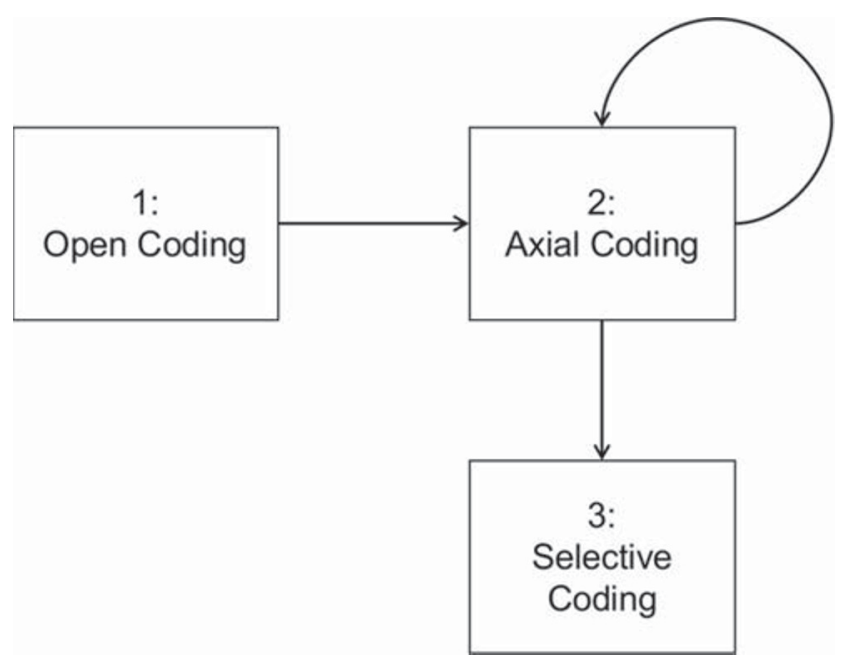

Fig. 1 Phases of data analysis
This represents a total of almost 6500 warnings issued from 2011 to 2016. The growing number of monitored municipalities in combination with the number of issued warnings demonstrates the severity and complexity of the disaster monitoring and early warning processes in Brazil.

To improve the accuracy of their critical decisions, Cemaden has expanded their network of IoT weather sensors to comprise 4375 rainfall gauges, 301 hydrological stations, 147 geological stations and 9 weather radar systems and also 650 meteorological sensors. Figure 2 shows examples of IoT weather sensors of Cemaden.

The central monitoring team at Cemaden works in sixhour shifts, starting at midnight each day. The size of the teams ranges from five to seven members and includes at least one specialist in each area of analysis. Each team must include specialists in hydrology, meteorology, geology, and a disaster analyst. The importance of their work lies in the fact that they are responsible for issuing warnings of possible disaster events and coordinate with the National Response Agency of Brazil, which then triggers response actions at the local level. Figure 3 shows the monitoring control room of Cemaden.

A typical daily process within the monitoring control room of Cemaden involves a meteorologist providing a weather report showing potential areas of high volume of rainfall based on information from satellites, meteorological stations and the network of IoT sensors. Once these areas have been identified, they are communicated to the hydrologist and the geologist operators, who then analyse historical and current data on the respective areas at risk to gain a better understanding of the situation on the ground; for example, the hydrologist investigates the volume of accumulated and current amount of rainfall. This data is retrieved from the IoT devices (e.g., hydrology stations or rainfall gauges) which is presented on a dashboard platform. Figure 4 shows a control room operator visualising the rainfall data from IoT weather sensors.

In addition to this platform, operators also use data analytics systems that implement machine learning algorithms to automate data processing and provide further insights to support decision making. Within the scope of this work, we focused our analysis on two systems: 1) the IDF (intensityduration-frequency) system that implements and generates rainfall IDF curves and 2) the web-based system of GIDES project that is responsible to detect landslides; both systems 
Fig. 2 IoT weather sensors of Cemaden. a Weather radar system. Source: Cemaden. b Rainfall gauge. Source: Anchieta City in the State of Espirito Santos

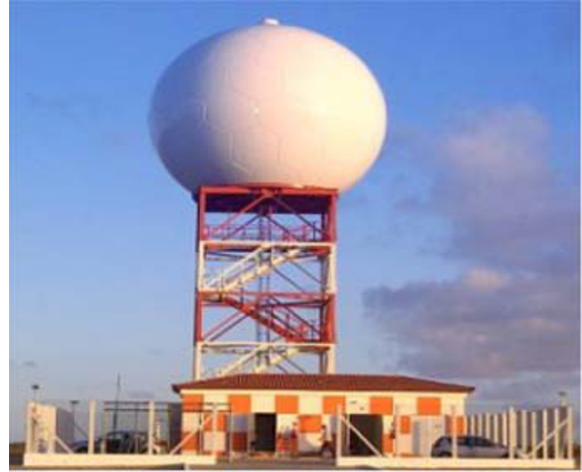

$\mathrm{a}$

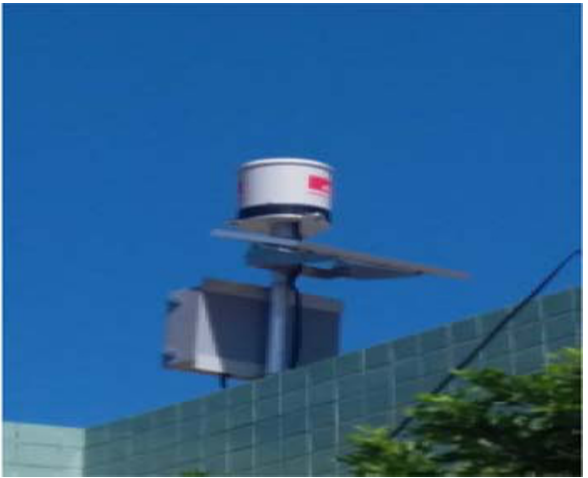

$\mathrm{b}$ utilise rainfall data as a basis for their analysis (Di Gregório et al. 2019). Using the IoT data and available models, the qualified experts of the control room assess the potential for a disaster and then both hydrologist and geologist operators decide whether to send a warning to the National Response Agency. The speed and accuracy of this decision making are vital because unless the warning is correct or reaches the Response Agency in time, proper response actions may not be triggered and the disaster may cause severe impacts on the local communities, including the loss of lives, property or damage of critical infrastructure. This explains why control room operators are continuously working under time pressure to make accurate and quick decisions.

\section{Findings}

Our findings are structured into two main emerging themes. First theme we explore is technology properties affecting situational awareness. This comprises the analysis of realtime IoT data and advanced computational models to enable better and faster decision making and situation awareness. The second theme is human properties affecting situational awareness. Here, qualified experts are relevant to improve understanding of the situation, while learned expertise supports developing appropriate mental models used to interpret data and make more critical decisions. The next sections show empirical evidence and discuss these themes. From the analysis of these first themes, a third theme emerged mediating conditions affecting situational awareness. This focuses on three topics related to collaboration among control room operators, as well as the balancing of human-system automation for data analysis and the role of local contextual data for supporting critical decision making.

\subsection{Technology Properties Affecting Situational Awareness}

As previously described, IoT weather sensors are used to support decision making in centralised control rooms. The following passage from a geologist (S2-3) working in the monitoring control room, explains the importance of IoT weather sensors as a key source of information to monitor local conditions even when they are not familiar with the actual location on the ground
Fig. 3 Monitoring control room of Cemaden

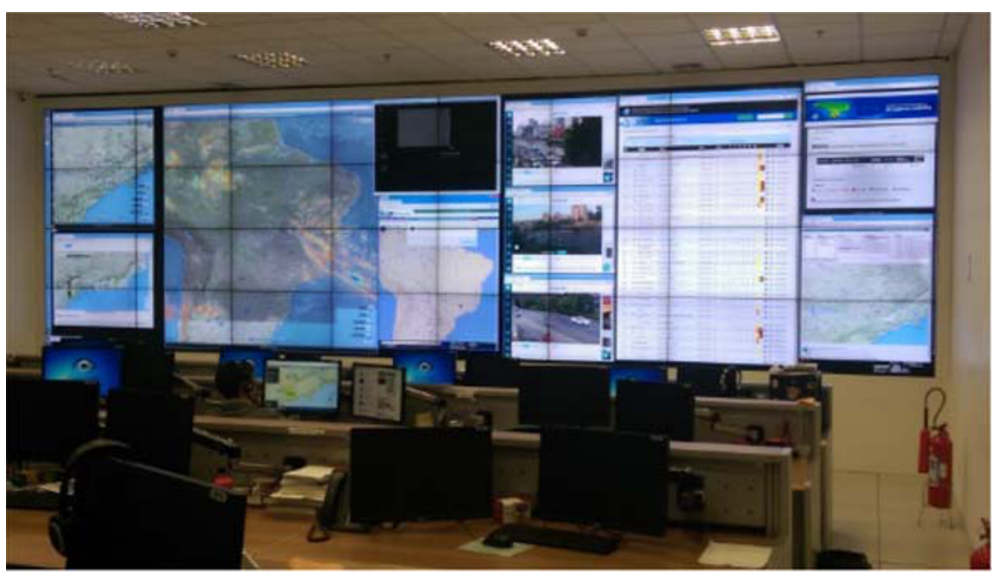


Fig. 4 Control room operator visualising data from IoT weather sensors. Source: Cemaden

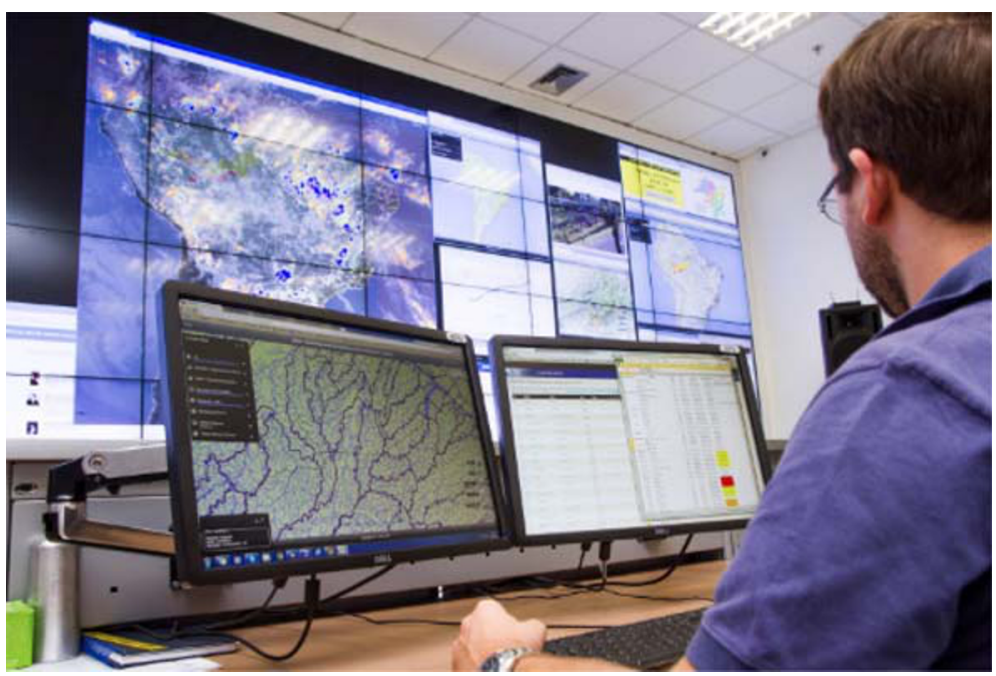

"These technologies are essential, weather radar, rainfall gauges, hydrological stations, satellites...since we do not know most of the places where we issue a warning...our baseline to [identify] landslides and [issue] warnings is the volume of rainfall and then these tools are fundamental to gain a notion of the volume of rainfall at the moment and if it will continue or not. So, because we do not know the region, we have to work based on the volume and intensity of rainfall. These tools are the best we have to collect this information.” (Geologist, S2-3).

However, while these technologies improve perception of local conditions, the growing number of IoT sensors and monitored cities adds complexity within the centralised control room. The high volume of data from unknown locations (e.g., places that were not monitored before) also requires decisions to be based on control room operators personal experiences and knowledge, instead of system recommendations. The importance of integrating various sources of data was stressed by a Disaster Analyst (S1-6) in the following statement:

"Nowadays, you have to filter. To make this analysis [understand the impact of a potential disaster event], you have to look at satellite imagery, historical data from rainfall gauges..there isn't a platform that helps you to make a quick search." (Disaster Analyst, S1-6).

Advanced computational models were seen as a solution to manage large volumes of IoT data and complex nature of information sources. Interestingly, the following quote from a Geologist (S2-1) explains how a data analytics system could automate some tasks in order to reduce the need to rely on empirical methods for decision making:

"Through the data analytics system [web-based system of GIDES project], you clearly structure the decision criteria. They [decisions] become more objective, more homogeneous in relation to operators from different backgrounds... It also makes the protocol more uniform. [It] adopts the same threshold." (Geologist, S2-1).

Participants believed that to reduce the overload of data they needed cooperation and collaboration between experts to improve the data analytics system that embodies decision rules defined in cooperation between Cemaden and Civil Defence. By doing that, both control room operators and emergency agencies on the ground would have a shared understanding of events, as explained in the following passage (S2-1):

"The system [web-based system of GIDES project] did not only change Cemaden, it also changed the stakeholders throughout the project... we established this link [between warning levels and their meanings]. What is the response action of civil defence when I send a moderate warning? If I send a very high warning, what is the action? This is clear now." (Geologist, S2-1).

Furthermore, when asked if a data analytics system would substitute or replace control room operators, there was a shared view among the participants that this is not possible as humans should give the "final vote" to issue critical warnings. This is due to the high responsibility associated with a decision, e.g., it can involve a massive evacuation, or mobilise resources from national agencies (e.g., Army, policeman, firefighters, etc).

Interviewees agreed that IoT sensors and data analytics systems had the potential to augment their perception of an ongoing situation, as suggested by Rai et al. (2019, $\mathrm{p}$ vi) who said that "where digital platforms enable human and AI agents to augment one another in order to perform a task". Our data indicate that expertise and working memory when comprehending a situation and projecting 
future risks. The reason is that in centralised control rooms, operators often rely on previous experiences to build mental models to interpret IoT data and assess ongoing situations. However, when projecting and anticipating risks, operators needed more contextual information beyond IoT data, as mentioned by a Meteorologist and a Geologist (S1-1 and S1-4, respectively) in the following quote.

"We do use a threshold table to analyse data...for
example, 120mm/24hrs at the coast, while, in some
municipalities like the Metropolitan Region of São
Paulo, the threshold is 80mm/72hrs...within the
control room, we created a simple standard if the
location is highly urbanised with recurrent issues
with hazards, the threshold is very low, for example,
$60 \mathrm{~mm} / 24 \mathrm{hrs"} \mathrm{(Geologist,} \mathrm{S1-4).}$

\subsection{Human Properties Affecting Situational Awareness}

Centralised monitoring control rooms are staffed with highly qualified experts in various disciplines. In disaster risk monitoring, this is relevant as disciplinary views from distinct backgrounds and experiences are joined to make critical decisions (Horita et al. 2018).

Experts in centralised control rooms need to coordinate knowledge to then determine the warning level and trigger a coordinated response to an upcoming disaster event. They rely on data but also on experiences acquired in previous situations to help understand local context. Coordinating and integrating perspectives across disciplines in this context is critical as stated in the following statement of a meteorologist working in a monitoring control room (S1-1).

"The geologist analyses these available data, but as we've relevant experience of the local conditions, we're able to make further considerations to clarify the situation." (Meteorologist, S1-1).

This statement shows that decisions rely on integrating input from all areas of expertise (e.g., hydrology and geology). It also highlights that they make decisions based on learning from past experiences shared with each other. This is important to improve the working and longterm memory of the group towards a better situational awareness in managing future events, which is then used to improve computational models. The following quotes from a Meteorologist and a Geologist (S1-1 and S2-2, respectively) explain how expertise and working memory are combined for gaining awareness of an ongoing situation.

"Sometimes, [the system] shows a high volume of rainfall, but it does not mean that it is going to happen in the next 24hrs. The operator then needs to analyse additional data sources to understand the overall situation.. to know whether or not the amount of rainfall is going to happen in the next 24hrs." (Meteorologist, S1-1).

"The meteorologist's gained knowledge is about how to interpret and understand the available data." (Geologist, S2-3).

Therefore, working and long-term memory are key elements for control room operators, particularly in the absence of equipment for monitoring, or when equipment has errors (e.g., broken sensors, or lack of energy). In these situations, operators rely on their past experiences to interpret data from other sources, to make a decision. Participants explained the importance of their experience and instinct to analyse situations. This is mentioned by a Hydrologist (S1-7) in the following quote

"When you do not have data, then we go on with our feelings. As I said, we have a lot of sensors, but we need more... We monitor around 1,000 municipalities...And sometimes the municipality has several rivers and only one sensor." (Hydrologist, S1-7).

Participants also mentioned the necessity to analyse multiple IoT sensors in order to properly understand local context. Comparing information from various data sources seemed to help build an understanding of the local context, as stated by a Hydrologist (S1-7).

"The satellite imagery I use for obtaining an overall picture of the whole country whereas the rainfall gauge is more useful when you are analysing a specific location." (Hydrologist, S1-7).

Balancing the integration between human and information systems was also critical. To support this integration, experts developed advanced models to process and derive insights from the numerous sources of data based on their experience in making decisions. These systems also had the potential to expand the knowledge of control room operators as they embody algorithms and models of analysis, helping when there is a lack of operators with specific knowledge. The embedding of models in the system was reinforced by two Geologist and a Disaster Analyst in the following statements (S2-1 and S2-4, respectively):

"It [web-based system of GIDES project] overcomes the lack of operators in some monitoring teams." (Geologist, S2-1).

"Before, I have to talk to the meteorologist to know his opinion. With the system [web-based system of GIDES project], I look at the graph and his opinion is shown there...I needed a technical justification to make a decision. The meteorologist gives it, but it is his word. Now, I have the graph and it's my responsibility 
to understand it and then make a decision." (Disaster Analyst, S2-1).

There there was resistance of operators to consolidate models and create advanced automated systems. This limited the integration of human and system in order to analyse environmental data to make better decisions, as one of the Geologists mentioned during the interviews (S2-2).

"Through automation, I can analyse different locations and distinct hazards in an agile manner... I have to monitor 955 municipalities...the system is there to assist you...the automated systems indicates where you should analyse in further details....but, when you try to implement it in the control room, it's hard because people do not want to migrate to something new. They want to use what they are used to." (Geologist, S2-2).

The balancing of human-system to comprehend the current situation was critical, but when projecting and anticipating future conditions, critical decision making goes beyond the advanced automated systems or IoT data. For these decisions, control room operators required local rich data on their expertise and knowledge learned from previous events to gain insights of local context. This was explained by a Meteorologist in the following statement.

"Part of meteorologist and the knowledge that he gained is also about knowing how to interpret the information. Sometimes, [the dashboard] shows a high volume of rainfall, but it doesn't mean that this will happen in the next 24 hours, he [meteorologist] needs to analyse other meteorological variables to understand...oh, this volume of rainfall in the current condition will happen in the next 2 or 3 hours." (Meteorologist, S1-1).

Figure 5 shows the data coding structure summarizing the findings in 1st- and 2nd- order themes, i.e., 1) technology properties affecting situational awareness, 2) human properties affecting situational awareness, and 3) mediating conditions affecting situational awareness. Further analysis of these themes sensitised by our theoretical concepts converged our attention on two broader developments representing positive

\section{Selected quotations}

- Satellite imagery provides an
overview of the situation
- Rainfall gauges help to analyse more
local contexts
- Other data sources are checked as
they supplement our own
- Decision-makers often analyse
different loT sensors to build
awareness of local context

- When embodying machine learning algoritms, the system would turn the decision-making more multidisciplinar - The system would minimize the lack of operators on the working shifts

- I don't have to check because I know the system will identify a critical event

- The team discussions are highly
valuable to determine the waming
level
- The geologist analyses these data,
but as we've some experiences,
we're able to make considerations to
clarify the situation
- High-qualified decision-makers have
to analyse different loT sensors to
build awareness of local context
- We're on our own when there aren't
data available
- Experiences from previous events
help to make decisions
- Experts need to know how to
examine the available data
Some locations we already have
experience so we know that the
threshold index is lower than other
places

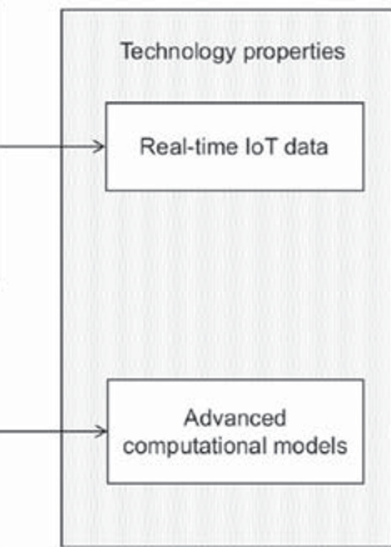

1st- and 2nd-Order themes

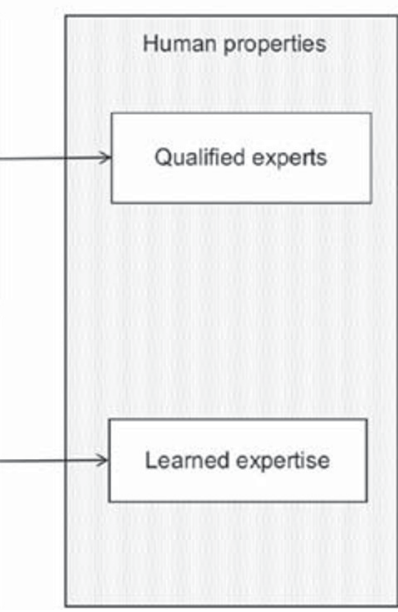

Fig. 5 Data coding structure. Adapted from Gioia et al. (2013)
Aggregate

dimensions

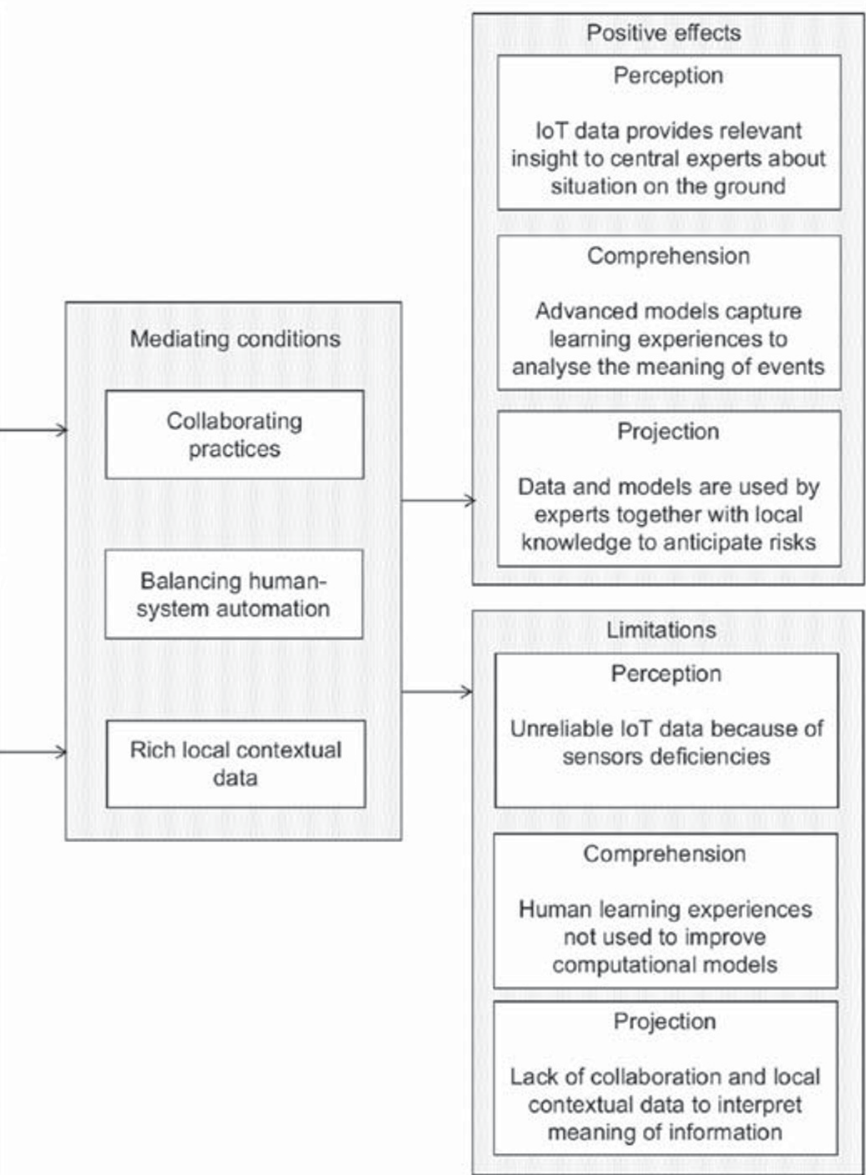


effects of the system on situational awareness and related limitations. We discuss these findings in the following section.

\section{Discussions}

We have examined the transformational effects of the adoption and use of a network of IoT weather sensors for situational awareness and decision making in Cemaden's national level centralised monitoring control room.

Drawing on the notion of Situational Awareness, we show how the network of IoT sensors provides central experts with critical information about the local conditions to improve the perception of decision makers of centralised control rooms. We further demonstrate that IoT data help operators in expanding their working memory and develop their longterm memory. This finding extends the results of Yang et al. (2013) by examining the use of IoT from the perspective of a centralised monitoring control room. Supplementary to Yang et al. (2013), we analyse empirical data on the use of IoT sensors for critical decision making, and explain mediating conditions that determine their effectiveness. Hence, real-time IoT data can be recognised as a precedent element for building and defining situational awareness by improving perception and comprehension of centralised highly qualified operators, who rely on these data to assess situations of risk. We also show that these operators collaborate to build and integrate advanced models in computing systems that further support comprehension.

Our study also highlights the limitations of relying on IoT data to make centralised critical management decisions. For instance, an operator often makes a decision based on a high volume of rainfall; however, different locations absorb different volumes of rainfall within the period of time. In other words, the operator's perception based on the data needs to be interpreted with more rich local contextual data of the situation. The study results show that IoT sensors allow operators to develop their perception and working memory to make decisions, but that they also need rich information to comprehend characteristics of the context of location they are not familiar with. This finding is relevant as it provides ways to overcome the issue pointed out by Stanton et al. (2001) on gaining awareness and making decisions of unknown locations in centralised control rooms. We therefore contribute to Stanton et al. (2001)'s work by providing empirical data collected that IoT is fundamental to structure working memory of current situations, as well as long-term memory and past experiences.

Our findings also show that to build situational awareness, qualified experts need to use available systems to gain access to required information. This notion was theoretically described in Endsley (2006)'s work and expanded in our study by providing empirical evidence that expertise and long-term memory are needed when processing data from different data sources. The study results indicate that working and long-term memory are developed and facilitated through the information exchange among control room operators. On the one hand, this reinforces the Stanton and Roberts (2020)'s notion of information exchange within centralised rooms by showing that such collaborating practices, in particular among expert and novice operators, are relevant and important to improve decision making in disaster risk monitoring. While, on the other hand, this result extends (de Walle et al. 2016)'s works insofar it shows that flexible information flow and exchange among operators is also relevant to improve team situational awareness.

Previous research provided evidence that automation is only desirable if the interplay human and system is aligned (Endsley 1988; Hawkley et al. 2005; Endsley 2017) and this is further explained by Rai et al. (2019). Our results demonstrate that advanced analytics systems could facilitate the work of new operators or operators that are not familiar with specific locations. This is because those systems would implement a part of data processing and provide rapid insights to control room operators. Interestingly, this finding adds to an emerging line of work focused on understanding how artificial intelligence and machine learning influences situational awareness (Goodman et al. 2017) insofar as it demonstrates that automated computational models potentially could aid in operators' perception of the situation to quickly develop their perception and comprehension of a situation. This finding is related to Scholl et al. (2019) which stated that both data integration and visualisation should reflect users' needs. In this study, we reinforce this finding and indicate that new technologies (e.g., machine learning or data visualisation tools) have a role to play in critical decision making in centralised control rooms. Our work also contributes to Jipp and Ackerman (2016)'s notion that data processing abilities and working memory capacities are fundamental to improve situational awareness. We show that in centralised control rooms, IoT and data analytics systems are highly relevant for gaining perception of the situation, but these technologies should still be combined with learned expertise in form of working and long-term memory of experts in other to comprehend and project future status.

Finally, the use of automated models on computing systems is useful to support operators in their area of expertise. Interestingly, during our work the participants mentioned that those technologies also have great potential to help them in making decisions on other domains; for instance, a hydrologist analysing a meteorology weather system. Drawing from knowledge management, this finding could be placed to what has been called "T-Shaped skills", i.e., a professional with depth knowledge in a particular discipline (the vertical part of " $T$ ") that also understands other 
disciplines (the horizontal part of "T") (Lee and Choi 2003). As a result, people are more likely to have broader discussions with one another, as well as "they have the ability both to combine theoretical and practical knowledge and to see how their branch of knowledge interacts with other branches" (Lee and Choi 2003, p. 193). This further highlights the positive impact of collaborating practices within the centralised control room. We found this quite interesting as it questions the result of Wickens (1996), which mentioned that automated systems may degrade the humans' knowledge of the environment. Our work indicates that through data analytics systems operators would expand their knowledge towards other areas of expertise and improve collaboration, ultimately contributing to achieving a better balance between humans and system.

\section{Conclusions}

The adoption of digital technologies can have deep transformational effects in organisations (Verhoef et al. 2019). A particular technology that has the potential to make profound transformations to different areas or organisations is IoT sensors and the use of computation analytics to process real-time data from networks of these sensors. Real time data from IoT sensors can provide vital information to improve awareness of local situations and thus support decision making in centralised control rooms.

We carried out an in-depth qualitative case study within a centralised monitoring control room of a Brazilian earlywarning centre that uses IoT sensor data to improve awareness of local events and conditions to control room operators. Our research generates contributions to both academic literature and practice. We provide an understanding of the transformational effects of modern technologies like IoT and analytics systems in building situational awareness in disaster risk monitoring. We capture three key insights relevant to both theory and practice. First, IoT data indeed heightened the perception and comprehension of control room operators of risk situations. Second, analytics systems are capable of embedding learned experiences in their models needed to improve comprehension of operators when analysing IoT data. Third, although these technologies have the potential to improve situational awareness, they are not sufficient. Rich local contextual information is necessary for projection and anticipation of risks, and the collaboration between experts and the balancing between humans and systems are also critical to decision making.

Although this work provides valuable contributions to theory and practice, it also has some limitations. Even though the case study was centered on disaster risk monitoring, the study results could be useful in several other application domains for understanding situational awareness of centralised control rooms. For example, possible application domains include nuclear power plants, or military command and control. Rigorous studies in these other scenarios are still required to establish the generalisability of our results. Furthermore, as the organisational settings in Cemaden might change over the time, the decisionmaking process, the agility in issuing a warning through decision support systems, or the composition of the teams of experts are constantly changing. These ongoing changes can challenge longitudinal comparisons.

We suggest that the effects identified in this work should be also evaluated in other organisational environments (e.g., business companies, universities, and hospitals). This could endorse our results by considering further characteristics and behaviours of the effects within control rooms for situational awareness. They could also contribute to the generalisability of our findings. Other cases can also raise unpredicted effects that were not present in our study, e.g., by examining tensions and situational awareness in the team/group level. Future lines of work could also capture the wider impacts of Cemaden on society.

Acknowledgments Flávio Horita would express his gratitute to the financial support provided by the Sao Paulo Research Foundation (FAPESP grant 2018/25805-5) and National Council for Scientific and Technological Development (CNPq grant 437937/2018-6). João Porto de Albuquerque's participation in this research is enabled by the project Waterproofing Data and financially supported by the Belmont Forum and NORFACE Joint Research Programme on Transformations to Sustainability (https://www.norface.net/program/ transformations-tosustainability/), which is co-funded by DLR/BMBF, ESRC/GCRF (grant ES/S006982/1), FAPESP and the European Commission through Horizon 2020. Finally, the authors would also like to thank the institutional support provided by Cemaden (Natural Disaster Monitoring and Early-Warning Centre) Brazil, as well as the insightful comments and contributions by Cemaden researchers and technologists.

Data Access Statement Due to ethical concerns, supporting data cannot be made openly available. Further information about the data and conditions for access are available at the Federal University of ABC Research Data Archive:http://dataverse.ufabc.edu.br/dataset. xhtml?persistentId=doi:10.5072/FK2/W2DYSU.

Open Access This article is licensed under a Creative Commons Attribution 4.0 International License, which permits use, sharing, adaptation, distribution and reproduction in any medium or format, as long as you give appropriate credit to the original author(s) and the source, provide a link to the Creative Commons licence, and indicate if changes were made. The images or other third party material in this article are included in the article's Creative Commons licence, unless indicated otherwise in a credit line to the material. If material is not included in the article's Creative Commons licence and your intended use is not permitted by statutory regulation or exceeds the permitted use, you will need to obtain permission directly from the copyright holder. To view a copy of this licence, visit http:// creativecommonshorg/licenses/by/4.0/. 


\section{Appendix A: Semi-structured questions adopted in the 1 st round of interviews}

The following semi-structured questions were adopted when conducting the 1st round of interviews in 2016.

- What are the activities (or tasks) that you perform at the control room of Cemaden?

- Is there any artefact, which guides the activities of the control room?

- What do you understand by risk management? How can we measure risk?

- How is a warning managed?

- How are the efficiency and accuracy of a warning assessed?

- What are the stakeholders involved with your work? How is communication with them?

\section{Appendix B: Semi-structured questions adopted in the 2 nd round of interviews}

The following semi-structured questions were adopted when carrying out the 2nd round of interviews in 2019.

- What are the activities (or tasks) that you perform at the control room of Cemaden?

- Is there any artefact, which guides the activities of the control room?

- What are the stakeholders involved with your work? How is communication with them?

- How is your experience with the advanced automated systems?

- How is a warning managed?

- How are the efficiency and accuracy of a warning assessed?

- Overall, do you think that the advanced automated systems can replace your tasks within the control room?

- What are the problems you think when adopting the advanced automated systems within the control room?

- Do you think some technical issues are affecting the adoption of advanced automated systems?

- Was there any situation in which you think the advanced automated systems will not support you?

\section{References}

Baptista, J., Stein, M.-K., Klein, S., Watson-Manheim, M.B., Lee, J. (2020). Digital work and organisational transformation: Emergent digital/human work configurations in modern organisations. The Journal of Strategic Information Systems, pp. 1-10.

Bordeleau, F.E., \& Felden, C. (2019). Digitally transforming organisations: a review of change models of industry 4.0. In Proceedings of the 27th European Conference on Information Systems (ECIS) (pp. 1-14). Stockholm and Uppsala: Sweden.
Burton, J.W., Stein, M.-K., Jensen, T.B. (2019). A systematic review of algorithm aversion in augmented decision making. Journal of Behavioral Decision Making, pp. 1-20.

Cak, S., Say, B., Misirlisoy, M. (2020). Effects of working memory, attention, and expertise on pilots' situation awareness. Cognition, Technology \& Work, 22(1), 85-94.

Cramer, J., \& Krueger, A.B. (2016). Disruptive change in the taxi business: the case of uber. American Economic Review, 106(5), 177-82.

de Walle, B.V., Brugghemans, B., Comes, T. (2016). Improving situation awareness in crisis response teams: an experimental analysis of enriched information and centralized coordination. International Journal of Human-Computer Studies, 95, 66-79.

Di Gregório, L.T., Graminha, C.A., Leal, P.J.V., Nery, T.D. (2019). Contributions of gides project for sediment disaster early warnings in brazil. International Journal of Erosion Control Engineering, 11(3), 73-84.

Endsley, M.R. (1988). Design and evaluation for situation awareness enhancement. In Proceedings of the Annual Meeting Human Factors Society, (Vol. 32 pp. 97-101). Los Angeles: SAGE Publications Sage CA.

Endsley, M.R. (1995). Toward a theory of situation awareness in dynamic systems. Human Factors, 37(1), 32-64.

Endsley, M.R. (2006). Expertise and situation awareness. In Ericsson, K.A., Charness, N., Feltovich, P.J., Hoffman, R.R. (Eds.) The Cambridge Handbook of Expertise and Expert Performance, Chapter 10 (pp. 633-651). Cambridge: Cambridge University Press.

Endsley, M.R. (2015). Situation awareness misconceptions and misunderstandings. Journal of Cognitive Engineering and Decision Making, 9(1), 4-32.

Endsley, M.R. (2017). From here to autonomy: lessons learned from human-automation research. Human Factors, 59(1), 5-27.

Endsley, M.R. (2018). Automation and situation awareness. In Automation and Human Performance (pp. 163-181). Routledge.

Endsley, M.R., Garland, D.J., et al. (2000). Theoretical underpinnings of situation awareness: a critical review. Situation Awareness Analysis and Measurement, 1, 1-24.

Fitzgerald, M., Kruschwitz, N., Bonnet, D., Welch, M. (2014). Embracing digital technology: a new strategic imperative. MIT Sloan Management Review, 55(2), 1.

Fracker, M.L. (1991). Measures of situation awareness: Review and future directions, Technical report, LOGUE (GEORGE E) INC MONTOURSVILLE PA.

Gioia, D.A., Corley, K.G., Hamilton, A.L. (2013). Seeking qualitative rigor in inductive research: notes on the gioia methodology. Organizational Research Methods, 16(1), 15-31.

Goodman, T.J., Miller, M.E., Rusnock, C.F., Bindewald, J.M. (2017). Effects of agent timing on the human-agent team. Cognitive Systems Research, 46, 40-51.

Gorman, J.C., Cooke, N.J., Winner, J.L. (2006). Measuring team situation awareness in decentralized command and control environments. Ergonomics, 49(12-13), 1312-1325.

Grønsund, T., \& Aanestad, M. (2020). Augmenting the algorithm: Emerging human-in-the-loop work configurations. The Journal of Strategic Information Systems, pp. 1-16.

Haddad, E.A., \& Teixeira, E. (2015). Economic impacts of natural disasters in megacities: the case of floods in São Paulo, Brazil. Habitat International, 45, 106-113.

Hausberg, J.P., Liere-Netheler, K., Packmohr, S., Pakura, S., Vogelsang, K. (2019). Research streams on digital transformation from a holistic business perspective: a systematic literature review and citation network analysis. Journal of Business Economics, 89(8), 931-963.

Hawkley, J.K., Mares, A.L., Giammanco, C.A. (2005). The human side of automation: Lessons for air defense command and control 
(arl-tr-3468). Technical report Adelphi, MD, Army Research Laboratory.

Hazen, B.T., Skipper, J.B., Ezell, J.D., Boone, C.A. (2016). Big data and predictive analytics for supply chain sustainability: a theorydriven research agenda. Computers \& Industrial Engineering, 101, 592-598.

Hinings, B., Gegenhuber, T., Greenwood, R. (2018). Digital innovation and transformation: an institutional perspective. Information \& Organization, 28(1), 52-61.

Horita, F.E.A., de Albuquerque, J.P., Marchezini, V. (2018). Understanding the decision-making process in disaster risk monitoring and early-warning: a case study within a control room in brazil. International Journal of Disaster Risk Reduction, 28, 22-31.

Horita, F.E.A., de Albuquerque, J.P., Marchezini, V., Mendiondo, E.M. (2017). Bridging the gap between decision-making and emerging big data sources: an application of a model-based framework to disaster management in brazil. Decision Support Systems, 97, $12-22$.

Jipp, M., \& Ackerman, P.L. (2016). The impact of higher levels of automation on performance and situation awareness: a function of information-processing ability and working-memory capacity. Journal of Cognitive Engineering and Decision Making, 10(2), 138-166.

Klein, H.K., \& Myers, M.D. (1999). A set of principles for conducting and evaluating interpretive field studies in information systems. Management Information Systems Quarterly, 23(1), 67-93.

Lee, H., \& Choi, B. (2003). Knowledge management enablers, processes, and organizational performance: an integrative view and empirical examination. Journal of Management Information Systems (JMIS), 20(1), 179-228.

Leonardi, P.M. (2015). Ambient awareness and knowledge acquisition: Using social media to learn "who knows what" and "who knows whom”. Management Information Systems Quarterly, 39(4), 747762.

Lo, F.-Y., \& Campos, N. (2018). Blending internet-of-things (iot) solutions into relationship marketing strategies. Technological Forecasting and Social Change, 137, 10-18.

Loebbecke, C., \& Palmer, J.W. (2006). Rfid in the fashion industry: Kaufhof department stores ag and gerry weber international ag, fashion manufacturer. Management Information Systems Quarterly Executive, 5(2), 69-79.

Lundin, A.C., Ozkil, A.G., Schuldt-Jensen, J. (2017). Smart cities: a case study in waste monitoring and management. In Proceedings of the 50th Hawaii International Conference on System Sciences (HICSS) (pp. 1392-1401). Waikoloa Beach, Puako, Hawaii, USA.

Mancheva, L., \& Dugdale, J. (2016). Understanding communications in medical emergency situations. In Proceedings Of the 49th Hawaii International Conference on System Sciences (HICSS) (pp. 198-206). Koloa, Hawaii, USA.

Marengo, J.A., \& Espinoza, J.C. (2016). Extreme seasonal droughts and floods in amazonia: causes, trends and impacts. International Journal of Climatology, 36(3), 1033-1050.

McAfee, A., \& Brynjolfsson, E. (2012). Big data: the management revolution. Harvard Business Review, 10, 59-68.

Messerli, P., \& Murniningtyas, E. (2019). Global Sustainable Development Report 2019: The Future is Now - Science for Achieving Sustainable Development Technical report, SecretaryGeneral, United Nations.

Oskam, J., \& Boswijk, A. (2016). Airbnb: the future of networked hospitality businesses. Journal of Tourism Futures, 2(1), 22-42.

Prince, C., Ellis, E., Brannick, M.T., Salas, E. (2007). Measurement of team situation awareness in low experience level aviators. The International Journal of Aviation Psychology, 17(1), 41-57.

Rai, A., Constantinides, P., Sarker, S. (2019). Editor's comments: Next-generation digital platforms: Toward human-ai hybrids. Management Information Systems Quarterly (MISQ), 43(1), iii-ix.
Rohmeyer, P., \& Zvi, T.B. (2009). Risk management decision making in ict for development. In Proceedings of the 2009 workshop of the AIS special interest group for ICT in global development (pp. 1-18). Phoenix, USA.

Runeson, P., \& Höst, M. (2008). Guidelines for conducting and reporting case study research in software engineering. Empirical Software Engineering, 14(2), 131-164.

Sakurai, M., \& Murayama, Y. (2019). Information technologies and disaster management:benefits and issues. Progress in Disaster Science, 2, 100012:1-100012:4.

Salas, E., Prince, C., Baker, D.P., Shrestha, L. (1995). Situation awareness in team performance: Implications for measurement and training. Human Factors, 37(1), 123-136.

Sarter, N.B., \& Woods, D.D. (1991). Situation awareness: a critical but ill-defined phenomenon. The International Journal of Aviation Psychology, 1(1), 45-57.

Scholl, H.J., Hubbell, K., Leonard, J. (2019). Information sharing and situational awareness: insights from the cascadia rising exercise of June 2016. In Proceedings of the 52nd Hawaii International Conference on System Sciences (pp. 3025-3035).

Schulman, P.R., \& Roe, E. (2011). A control room metric for evaluating success and failure in high reliability crisis management. Policy and Society, 30(2), 129-136.

Schwertner, K., Zlateva, P., Velev, D. (2018). Digital technologies of industry 4.0 in management of natural disasters. In Proceedings of the 2nd International Conference on E-Commerce, E-Business and E-Government (pp. 95-99).

Seaman, C.B. (1999). Qualitative methods in empirical studies of software engineering. IEEE Transactions on Software Engeneering, 25(3), 1-16.

Seebach, C., Beck, R., Pahlke, I. (2011). Situation awareness through social collaboration platforms in distributed work environments. In Proceedings of the 32nd International Conference on Information Systems (ICIS) (pp. 1-22). Shanghai, China.

Shah, S.A., Seker, D.Z., Hameed, S., Draheim, D. (2019). The rising role of big data analytics and iot in disaster management: Recent advances, taxonomy and prospects. IEEE Access, 7, 54595-54614.

Sheth, A. (2016). Internet of things to smart iot through semantic, cognitive, and perceptual computing. IEEE Intelligent Systems, 31(2), 108-112.

Shrestha, Y.R., Ben-Menahem, S.M., von Krogh, G. (2019). Organizational decision-making structures in the age of artificial intelligence. California Management Review, 61(4), 66-83.

Stanton, N.A., Chambers, P.R.G., Piggott, J. (2001). Situational awareness and safety. Safety Science, 39(3), 189-204.

Stanton, N.A., \& Roberts, A.P.J. (2020). Better together? investigating new control room configurations and reduced crew size in submarine command and control. Ergonomics, 63(3), 307-323.

Stevens-Adams, S., Cole, K., Haass, M., Warrender, C., Jeffers, R., Burnham, L., Forsythe, C. (2015). Situation awareness and automation in the electric grid control room. Procedia Manufacturing, 3, 5277-5284.

Stieglitz, S., Mirbabaie, M., Schwenner, L., Marx, J., Lehr, J., Brünker, F. (2017). Sensemaking and communication roles in social media crisis communication. In Proceedings of the 2017 International Conference on Wirtschaftsinformatik (pp. 1333-1347). St. Gallen, Switzerland.

Strauss, A., \& Corbin, J. (1998). Basics of qualitative research techniques. Sage publications Thousand Oaks, CA.

Valecha, R., Sharman, R., Rao, R., Upadhyaya, S. (2012). Design principles for emergency collaborative systems: A situation awareness study of buffalo plane crash. In Proceedings of the 18th American Conference on Information Systems (AMCIS) (pp. 111). Seattle, USA.

Velev, D.G. (2011). Internet of things: analysis and challenges. Economic Alternatives, 2, 99-109. 
Verhoef, P.C., Broekhuizen, T., Bart, Y., Bhattacharya, A., Dong, J.Q., Fabian, N., Haenlein, M. (2019). Digital transformation: a multidisciplinary reflection and research agenda. Journal of Business Research, pp. 1-13.

von Krogh, G. (2018). Artificial intelligence in organizations: New opportunities for phenomenon-based theorizing. Academy of Management Discoveries, 4(4), 404-409.

Wessel, L., Baiyere, A., Ologeanu-Taddei, R., Cha, J., Jensen, T. (2020). Unpacking the difference between digital transformation and it-enabled organizational transformation. Journal of Association of Information Systems, pp. 1-57.

Westerlund, M., Leminen, S., Rajahonka, M. (2014). Designing business models for the internet of things. Technology Innovation Management Review, pp. 5-14.

Wickens, C.D. (1996). Situation awareness: impact of automation and display technology. In Proceedings of the Situation awareness: Limitations and Enhancement in the Aviation Environment (AGARD) (pp. k2-1-k2-13). Brussels, Belgium.

Wickler, G., \& Potter, S. (2009). Information-gathering: from sensor data to decision support in three simple steps. Intelligent Decision Technologies, 3(1), 3-17.

Yang, L., Yang, S.H., Plotnick, L. (2013). How the internet of things technology enhances emergency response operations. Technological Forecasting and Social Change, 80(9), 18541867. Planning and Foresight Methodologies in Emergency Preparedness and Management.

Yin, R. (2002). Case study research: design and method. S. P. Inc.

Publisher's Note Springer Nature remains neutral with regard to jurisdictional claims in published maps and institutional affiliations.

Flávio Horita is an Assistant Professor at the Center of Mathematics, Computation, and Cognition of Federal University of ABC, Brazil. He received his $\mathrm{PhD}$ in Computer Science and Mathematical Computing from the University of São Paulo, Brazil (2017). Flávio held positions as a Visiting Research Fellow at Warwick Business School of the University of Warwick, UK (2019-2020) and Visiting Scholar at the European Research Center for Information Systems (ERCIS) of the WWU-Münster University, Germany (2014-2015). He is Group Leader of the Sociotechnical Systems Research Initiative (Nexus), as well as an Associate Member of the Risk Management Lab and the NUVEM Strategic Unit of the Federal University of ABC, Brazil. His research interest lies in an interdisciplinary spectrum of software system engineering (i.e., artificial intelligence for software modelling, system-of-systems, and applied software engineering) and digital transformation (i.e. society and business transformation).
João Baptista is Associate Professor at Warwick Business School where he has been since 2006. Before this, he was a researcher and completed his $\mathrm{PhD}$ in Information Systems at the London School of Economics. His research focuses on the use of digital media in the workplace and to capture their effects on dynamics and structures of organisations. He won awards for best research publication of 2010 by Association of Information Systems and by the Journal of Strategic Information Systems. He is founder of the AIS special interest group on Changing Nature of Work and co-editor of the Special Issue of the Journal of Strategic Information Systems on "Strategic Perspectives of Digital Work and Organisational Transformation". Joao has been Visiting Professor at LUISS Guido Carli University in Rome, Italy and also at Bentley University in Boston, USA.

João Porto de Albuquerque is Professor and Director of the Institute of Global Sustainable Development at the University of Warwick, and a Turing Fellow at The Alan Turing Institute. He is a geographer and computer scientist with an interdisciplinary background, working in the fields of information systems, digital geography, geographic information science and global sustainable development. João is currently leading a research programme centred around the empowerment of vulnerable and deprived communities with citizen-generated data to improve resilience to health and environmental risks. To support this research, he has secured competitive research funds from diverse national and international funding bodies for transdisciplinary projects in collaboration with partners around the globe (e.g. Bangladesh, Brazil, Colombia, Kenya, Nigeria, Pakistan). 